J. Neurol. Neurosurg. Psychiat., 1959, 22, 338

\title{
THE PROGNOSIS FOR AFFECTIVE ILLNESS WITH OVERT ANXIETY
}

\author{
BY \\ LINDSAY WALKER \\ From Netherne Hospital, Coulsdon, Surrey
}

Not the least of our problems in psychiatry is the ubiquitous anxiety state. These patients are an unsatisfactory group because there seem to be no established indications for treatment, and it is rare to find anyone who is prepared to give an unequivocal prognosis. This is due in large measure to the fact that anxiety is a word having varying connotations, so that "anxiety state" is not a precise term. Even if anxiety is strictly defined there are still a number of different conditions having this symptom in common, and which may all therefore be reasonably called anxiety states. For this reason questions about the treatment of anxiety states have little real meaning, and it is easy to see how such methods as individual psychotherapy, group therapy, tranquillizers, modified insulin, and even electroconvulsive therapy, may all be mentioned at some time during the course of a discussion on this subject. Until we have a working classification and some agreement about the untreated prognosis for these illnesses, there can never be unanimity about the indications for treatment, or any useful evaluation of the treatments.

This article is concerned with the classification of illness confidently diagnosed as affective (as opposed to schizophrenic or organic), and in which anxiety is the cardinal presenting symptom. Illness in which anxiety was incidental, but not predominant, has been excluded. It is probably because of this that patients, with one exception, are from the age group 20 to 35 years.

It is imperative to be clear about the boundaries of the subject under investigation, and "anxiety" in this context refers to manifest, overt, or freefloating anxiety. This is variously described by the patient as a feeling of fear, panic, tension, or, more descriptively, as a sensation of being wrought up, or of expecting something unpleasant to happen. Physiological concomitants of fear are almost invariably present. Common ones are described as palpitations, rapid heart beats, missed heart beats, or a sudden empty feeling in the pit of the stomach. The less common are complaints of diarrhoea, frequency of micturition, and a sudden sensation of dizziness or instability. The fear may be nameless, or secondary elaboration may occur so that anxiety becomes centred, for instance, on the idea of heart disease or death. Bodily symptoms may occasionally be the first or main complaint, but the feeling of acute anxiety is always present.

This definition of anxiety excludes from the study all those anxiety states, anxiety hysterias, or organ neuroses in which somatic symptoms are unaccompanied by manifest anxiety or tension.

All the patients considered were under my care and supervision from the onset of their illness. They were selected from among consecutive outpatients using the criteria listed below, and were seen in departments serving rural, urban, and metropolitan-suburban districts of Surrey and Sussex. Throughout the study the treatment was not definitive, and consisted of varying admixtures of superficial reassurance and amylo-barbitone, grain $\frac{3}{4}$. It can reasonably be described as expectant.

The fundamental basis of classification was prognostic. In addition, it seemed to me that other reasonably objective criteria having possible predictive value could be set up based on the mode of onset, and the method of progression or course of the illness.

Presenting symptoms were used for classification; some patients changed their symptoms as time passed, but they were not reclassified.

The criteria are as follows :-

\section{Prognostic Criteria}

Group 1.-Patients show complete recovery without residual symptoms. Follow-up after recovery was not less than three months.

Group 2.-Patients fail to recover. The minimum period of continuous illness for inclusion in this group was two years.

Group 3.-Patients show partial recovery, or relapse rapidly after apparent recovery. The whole 
of this group was arrived at by a process of exclusion from Groups 1 and 2 , and not by positive selection.

Patients were not included in Group 2 until they had been ill continuously and without remission for two years.

\section{Mode of Onset}

Instantaneous. - This is to be interpreted literally. The illness begins suddenly, and without warning, and is then fully established.

Rapid.- The illness builds up over a matter of hours, or a few days at the most. If the process involves days there may be some fluctuation in the intensity of the upward trend of the symptoms.

Gradual.-Symptoms increase in frequency and severity over a period of weeks or months until a constant level is attained. Frequency as well as severity is included, so that the group includes a common type in which the presenting attack may be instantaneous, but recurrences are initially sporadic and only gradually increase in frequency until a pattern is established.

\section{Progression or Course}

Episodic without Precipitation.-The illness occurred in discrete bouts with a well-defined onset and termination, and in the interval the patient was normal, or at least his state was in no way comparable with that during attacks. There was no apparent cause for the attacks.

Episodic with Precipitation.-In this group attacks were related, for instance, to the necessity to go out or to meet people. The patient was well between attacks.

Constant but with Unprecipitated Exacerbation.The patients here experienced a constant state of anxiety with episodic increases in tension for no apparent reason.

Fluctuating.-This is certainly a heterogeneous group. The first general characteristic was a more or less constant level of tension which lacked the sustained intensity of that in the group "constant but with unprecipitated exacerbation". The tension abated completely at times in some individuals. It seemed to be a constitutional defect rather than an acquired symptom. Superimposed were exacerbations of tension, usually on having to perform incidental or routine acts which would constitute a minimal stress for the average individual.

One group of patients was excluded from the study despite the fact that they showed anxiety as a major symptom. These were those with phobic states. They were excluded because they are already identifiable clinically as a group, and are, therefore, able to be classified (Mayer-Gross, Slater, and Roth, 1954). This is not to imply that they do not merit investigation on other accounts, or, in particular, that the prognosis for this illness is well established. Patients excluded had to conform with the following description. They showed anxiety as a major symptom, and they experienced this in a particular setting, or by contemplation that this situation might arise. The cause of the anxiety lay in the specific fear of what might happen in the particular situation. The fear was recognized by the patient as irrational, and was resented, but without influencing the anxiety. These phobic states are to be distinguished from superficially similar states in which free-floating anxiety gradually becomes fixed to one or more situations. The latter syndrome was included in the study. It is less well defined, and has more variants than the phobic states. Because the anxiety becomes centred, for instance, on crowds or queues, the illness may be designated as a specific phobia, e.g., agarophobia, or a phobic anxiety state, and there is frequently no attempt made at differentiation from the phobic states. In practice, phobic state, phobic anxiety state, and phobia tend to be used indiscriminately. Examples may serve to underline differences.

The patient with a phobic state may be unwilling to go to the cinema because of the intrusive idea that the gallery will fall and kill her. This idea is resented and resisted, but the patient remains intensely anxious so long as she is in the cinema.

The patient with a phobic anxiety state experiences anxiety symptoms, and comes to fear going out in case she has an incapacitating attack in public. The attacks are infrequent at home, but increase in frequency and severity the further the patient goes from home. There is no compulsive element involved here, and the patient does not resist or resent the thought which keeps her at home, because it is the logical sequel to the anxiety attacks which are the primary symptom.

\section{Results}

The classification of 111 patients is shown in Fig. 1. Tests show that in form of onset and ultimate prognosis the episodic without precipitation group is highly significantly different from the others.

\section{Discussion}

This is a clinical study having as its objective the classification of patients with overt anxiety. The criteria were chosen because they were reasonably objective, and because I hoped they might have predictive value. The results establish significant 
$\begin{array}{llll}\text { PROGNOSTIC GROUP I II IY IPE OF PROGRESSION } & \text { II }\end{array}$

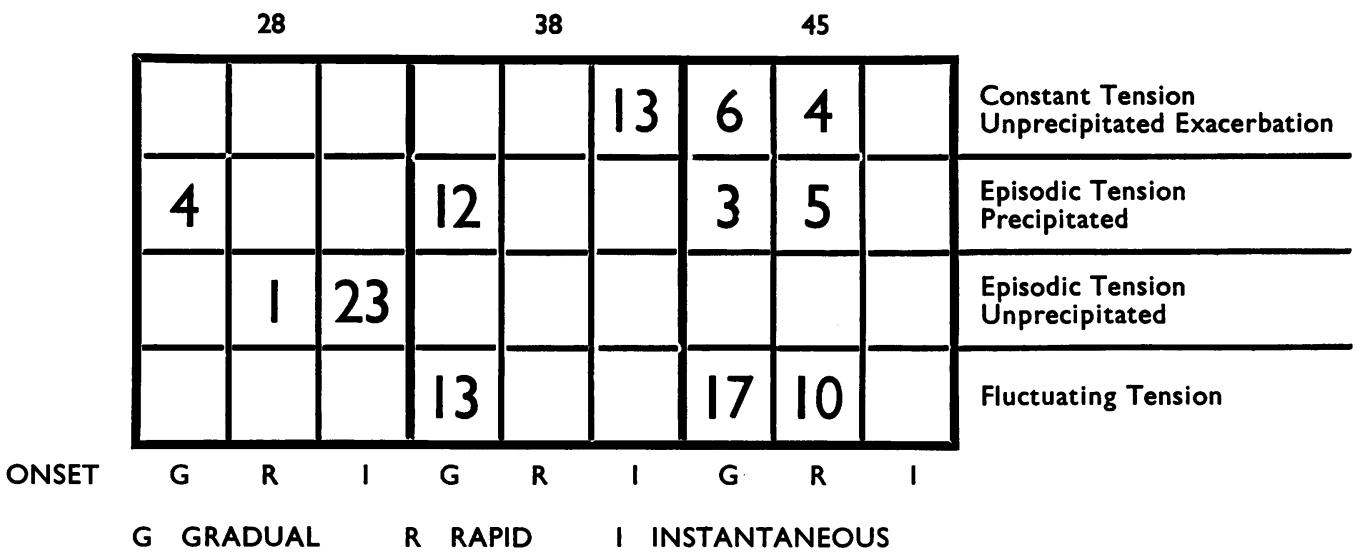

Fig. 1.-Classification of 111 patients with anxiety symptoms.

relationships, but, with one exception, it is not possible to make out a case for the delineation of clinical syndromes. The exception is that group of patients described as "episodic without precipitation" and for whom the onset of the illness is almost always instantaneous and the outcome invariably good.

The following is a description of a typical case :-

The onset of acute anxiety is instantaneous, unrelated to circumstances at the time, and comes as a complete surprise to the patient. There may be associated somatic symptoms other than those of pure anxiety, for instance, odd paraesthesiae. The anxiety attacks are episodic, of an order of frequency of two per day, tending to maintain a schedule with individual patients. The episodes are sudden in onset, but die away more gradually. Between attacks the patient is relatively normal, although tending to be irritable or morose. Throughout the illness the patient resists the onset of attacks, and indulges in furious self-recriminations because of his or her inability to prevent them. Patients become voluble on this point so that I have seen them regarded as hysterical.

Commonly the patients have vague, ill-formulated, gloomy forebodings, and become reluctant to plan, and are increasingly inert. This gloomy feeling may be associated with intrusive thoughts that they have organic diseases, which they resist and regard as futile, but which they cannot quite dismiss. One patient said, "My wife wants new curtains, and we have got all the patterns, but now I cannot take an interest, because somehow I feel I shall not live to see them. I know this is silly, and I could kick myself". Depression as such is rarely a specific complaint.
Sleep and appetite are variable, and of little assistance in diagnosis. Weight is lost, but rarely more than a stone.

Previous attacks, all of them self limiting, had occurred in five of my cases, although almost all had had transient attacks in which episodes had occurred daily for up to 10 days, but the patient had not been to a doctor.

Personality was independent and energetic.

I find the episodic without precipitation type of illness consistently diagnosed and accepted as an anxiety state, whereas I believe the better diagnosis to be depression with episodic anxiety. The anxiety symptoms are so prominent that depressive symptoms may fail to be elicited, or the clinician may be misled into confusing symptoms with illness as is frequently the case when the word hysterical is used.

Briefly, the reasons for regarding the illness as depressive are as follows :-

Anxiety may be a symptom of depression (Lange, 1928 ; Lewis, 1934). Depressives get well (Ross, 1923). There is a well-defined onset resulting in a change of behaviour (Lange, 1928). The onset is in the third and fourth decades (Slater, 1938). Previous attacks are not uncommon (Rennie, 1939, 1942) and will be higher if the transient attacks are included. In addition, gloomy foreboding, selfreproach, and obsessional thinking, although not perhaps obtrusive, are frequently present.

Although the remaining 87 cases do not fall so readily into clinically recognizable groups, it is still possible to apply the results usefully to clinical problems. This can be done entirely objectively without making a formal diagnosis. For instance, where anxiety is of instantaneous onset, it can be 
seen from Fig. 1 that patients fall into two groups, and the prognosis is good or bad, but never indifferent. The distinction between the alternatives may be made by deciding whether the patient is constantly tense or relatively normal between episodes.

Alternatively, clinical description may be invoked, and after a diagnosis has been formulated, the place of the patient in Fig. 1 may be assigned by applying the criteria of onset and course. If this is done it will be found that patients with undifferentiated tension states (Curran and Partridge, 1952; Pippard, 1955) fall mainly into the group "constant but with unprecipitated exacerbation". For these patients the outlook is never good and whether it is bad or indifferent seems to depend on the type of onset. Other chronic and undifferentiated tension states fall into the group "fluctuating". The patients I have called phobic anxiety states fall mainly into the group "episodic with precipitation". Patients who, in practice are loosely called recurrent anxiety states or merely neurotics, appear in the group "fluctuating". Having assigned a patient to a place in this table it is then possible to make inferences about the prognosis.

One type of patient who upsets an attempt at classification such as this is the transitional case which changes type from time to time. Some of these are true hysterics in whom tension is as much a conversion symptom as paralysis. In other instances it seems that affective illness must be an interacting system in which consistent patterns of reaction are the rule but in which not infrequently one type may be diverted as it were to a different set of circuits. It is noteworthy that in only about a quarter of my cases was this circuit spontaneously reversible. That is, spontaneous recovery was restricted to about $25 \%$ of the cases, and these were almost all those of the depressive type.

\section{Summary}

Patients presenting themselves with overt anxiety as defined have been classified using outcome as the primary criterion. Two subsidiary sets of criteria relating to onset and course use time relationship as their main basis for selection.

Significant inter-relationships are established, and the existence of one group is claimed as a discrete clinical entity probably best described as falling in the depressive section of the affective system of reactions. This group accounts for the majority of spontaneous recoveries among the anxiety states.

I am grateful to Dr. J. P. S. Robertson for statistical advice and to Messrs. Hulme and Cooper of the laboratory for preparing the chart.

\section{REFERENCES}

Curran D. and Partridge, M. (1952). In British Surgical Practice. Surgical Progress, p. 162. Ed. E. Rock Carling and J. Paterson Ross. Butterworth, London.

Lange, J. (1928). In Handbuch der Geisteskrankheiten, ed. O. Bumke, Vol. 6. Springer, Berlin.

Lewis, A. J. (1934), J, ment. Sci., 80, 277.

Mayer-Gross, W., Slater, E. T. O... and Roth, M. (1954). Clinical Psychiatry. Cassell, London.

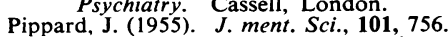

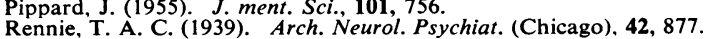
Rennie, T. A. C. (1939). Arch. Neurol. Psych

Ross, T. A. (1923). The Common Neuroses. Arnold, London.

Slater, E. (1938). Z. ges Neurol. Psychiat., 162, 794 